\title{
An effective survey method for studying volant species activity and behavior at tall structures
}

\author{
Brynn E Huzzen ${ }^{1}$, Amanda M Hale ${ }^{2}$, Victoria J Bennett ${ }^{\text {Corresp. } 1}$ \\ ${ }^{1}$ Department of Environmental Sciences, Texas Christian University, Fort Worth, TX, United States \\ 2 Department of Biology, Texas Christian University, Fort Worth, TX, United States \\ Corresponding Author: Victoria J Bennett \\ Email address: v.bennett@tcu.edu
}

Anthropogenic modification of air space presents a growing threat to wildlife, particularly volant species. Thus, it is essential to understand wildlife-interactions with tall structures to implement effective mitigation strategies. Yet, we are currently lacking standard protocols for visual surveys of wildlife behavior at such heights. Our study sought to determine an effective, repeatable method using readily available night vision and thermal technology to survey wildlife at tall structures. Using bats as the taxonomic group of interest, we 1) created a key to identify bats and their behavior, 2) compared the effectiveness of 2 different technologies, and 3) assessed optimal equipment placement to visually capture bat activity and behavior in proximity to wind turbine towers. For the latter, we tested thermal cameras at 4 distances from the base of the tower. The results of our study revealed that thermal cameras captured $\sim 34 \%$ more flying animals than night vision at a $2 \mathrm{~m}$ distance. However, due to the heat signature of the turbine towers themselves, it was challenging to identify behaviors and interactions that occurred in close proximity to the towers. In contrast, it was difficult to identify bats approaching the towers using night vision, yet we were able to clearly observe interactions with the towers themselves. With regards to equipment placement, we visually captured more bats with the thermal cameras placed $2 \mathrm{~m}$ from the tower base compared to farther distances. From our findings, we recommend that when using either thermal or night vision technology at tall structures, they be placed $2 \mathrm{~m}$ from the base to effectively observe interactions along the length of these structures. In addition, we further recommend that consideration be given to the use of these two technology types together to effectively conduct such surveys. If these survey techniques are incorporated into standard protocols, future surveys at a variety of tall structures are likely to become comparable and repeatable, thereby more effectively informing any mitigation strategies that may be required. 


\author{
1 An effective survey method for studying volant species \\ 2 activity and behavior at tall structures \\ 3 Brynn E. Huzzen ${ }^{1}$, Amanda M. Hale ${ }^{2}$, Victoria J. Bennett ${ }^{1}$ \\ $4{ }^{1}$ Department of Environmental Sciences, Texas Christian University, Fort Worth, Texas, United \\ 5 States of America \\ $6 \quad{ }^{2}$ Department of Biology, Texas Christian University, Fort Worth, Texas, United States of \\ 7 America \\ 10 Corresponding Author: \\ 11 Victoria J. Bennett \\ 12 v.bennett@tcu.edu
}




\section{Abstract}

15 Anthropogenic modification of air space presents a growing threat to wildlife, particularly volant

16 species. Thus, it is essential to understand wildlife-interactions with tall structures to implement

17 effective mitigation strategies. Yet, we are currently lacking standard protocols for visual surveys

18 of wildlife behavior at such heights. Our study sought to determine an effective, repeatable

19 method using readily available night vision and thermal technology to survey wildlife at tall

20 structures. Using bats as the taxonomic group of interest, we 1) created a key to identify bats and

21 their behavior, 2) compared the effectiveness of 2 different technologies, and 3) assessed optimal

22 equipment placement to visually capture bat activity and behavior in proximity to wind turbine

23 towers. For the latter, we tested thermal cameras at 4 distances from the base of the tower. The

24 results of our study revealed that thermal cameras captured $\sim 34 \%$ more flying animals than night

25 vision at a $2 \mathrm{~m}$ distance. However, due to the heat signature of the turbine towers themselves, it

26 was challenging to identify behaviors and interactions that occurred in close proximity to the

27 towers. In contrast, it was difficult to identify bats approaching the towers using night vision, yet

28 we were able to clearly observe interactions with the towers themselves. With regards to

29 equipment placement, we visually captured more bats with the thermal cameras placed $2 \mathrm{~m}$ from

30 the tower base compared to farther distances. From our findings, we recommend that when using

31 either thermal or night vision technology at tall structures, they be placed $2 \mathrm{~m}$ from the base to

32 effectively observe interactions along the length of these structures. In addition, we further

33 recommend that consideration be given to the use of these two technology types together to

34 effectively conduct such surveys. If these survey techniques are incorporated into standard

35 protocols, future surveys at a variety of tall structures are likely to become comparable and

36 repeatable, thereby more effectively informing any mitigation strategies that may be required. 


\section{Introduction}

38 Air space is important habitat for many volant species, providing foraging sites, mating

39 opportunities, vantage points for predators, and access to resources (Alerstam 1979; Avila-Flores

40 \& Fenton 2005; Diehl 2013). Thus, any anthropogenic use of the air space can potentially have

41 an impact. For example, airplanes are estimated to strike over 25,000 birds annually in the

42 United States (Erickson 2005; Pfeiffer, Blackwell \& DeVault 2018). Yet, we have modified the

43 air space in many other ways as well. For decades, we have been installing tall anthropogenic

44 structures (defined here as lattice or monopole towers $>20 \mathrm{~m}$ in height) including electrical,

45 radio, meteorological, satellite, and cell phone towers, along with power lines and skyscrapers.

46 Studies have confirmed that such tall structures can disorient migratory birds (Avery, Springer \&

47 Cassel 1976; Gehring, Kerlinger \& Manville 2009), reduce breeding success (Dahl et al. 2012),

48 and are a source of bird and bat fatalities due to collisions (Crawford \& Wilson Baker 1981;

49 Timm 1989; Longcore et al. 2012; Loss, Will \& Marra 2015). Moreover, the construction and

50 installation of wind turbines in the last few decades have led to increased bird and bat fatalities

51 (Arnett \& Baerwald 2013; Erickson et al. 2014). Projections of annual mortality vary, but studies

52 have estimated between $140,000-573,000$ bird and $600,000-888,000$ bat fatalities/yr in the

53 United States (Hayes 2013; Loss, Will \& Marra 2013; Smallwood 2013; Arnett et al. 2016).

54 Demographic studies predict that if these mortality rates continue, they could lead to population

55 declines in certain species (de Lucas et al. 2012; Balotari-Chiebao et al. 2016; Frick et al. 2017;

56 Rodhouse et al. 2019).

57 Yet, the threats caused by the modification of the air space are increasing with ongoing

58 wind energy installations and other technological advances associated with urbanization, such as

59 an increase in cell phone towers (Lu, McElroy \& Kiviluoma 2009; Vasenev et al. 2018). There 
60 is, therefore, a need to 1) better understand the impacts of air space modification on wildlife, and

61 2) potentially implement mitigation strategies that can effectively alleviate such impacts.

While some strategies have already been developed and are now standard practice, such

63

64

65

66

67

68

69

70

71

72

73

74

75

76

77

78

79

80

81

82

as avian-safe protections on electrical wires (Avian Power Line Interaction Committee 2006),

there are still areas of research that need to be explored in order to develop further mitigation at tall structures. For example, research is currently investigating the effectiveness of acoustic and visual deterrents intended to discourage birds and bats from approaching structures, such as wind turbines (e.g., Arnett et al. 2013; Swaddle \& Ingrassia 2017; Goller et al. 2018; Dwyer et al. 2019), as well as operational minimization strategies in which wind turbine blades are prevented from spinning at times when bats are most likely at risk of collision (e.g., Arnett et al. 2011; Martin et al. 2017; Hayes et al. 2019). While these approaches can be effective, there is still much room for improvement as we do not fully understand why and how different species are interacting with tall structures (Wang, Wang \& Smith 2015; Bennett \& Hale 2018; Bernardino et al. 2018). There are three broad hypotheses for bat interactions with tall structures: 1)

interactions with tall structures are purely coincidental; 2) resources, such as shelter, mating opportunities, movement corridors, foraging sites, or water sources, are available in close proximity to the structures, thus increasing the probability of interaction; and 3) the structures themselves provide or are perceived to provide a resource, thereby attracting bats to them (Cryan $\&$ Barclay 2009). Due to the high numbers of bat fatalities reported at wind turbines, there have been several of studies to date that have focused on discerning which of these hypotheses may explain why bats are coming into contact with these structures (e.g., Bennett \& Hale 2014, Rydell et al. 2016; Bennett \& Hale 2018, Long et al. 2011). One such study, for example, by Jameson and Willis (2014) suggested that bats were attracted to tall anthropogenic structures 
83 during migration and found that the bat calls recorded at such structures were primarily

84 composed of social calls indicative of mating behavior. Another study by Bennett et al. (2017)

85 found bat feces in turbine door slats, indicating bats were using wind turbines as night roosts.

86 While a further 3 studies have examined the stomach contents of bat carcasses retrieved from

87 beneath wind turbines (Valdez \& Cryan 2013; Rydell et al. 2016; Foo et al. 2017), finding that

88 many of the stomachs were not only full (a sign of recent foraging), but also contained a similar

89 composition of invertebrates to those on and around the wind turbines.

90 Typically, behavioral surveys involving direct observations provide an effective method

91 of exploring wildlife interactions, but such surveys conducted at height have, until recently, been

92 challenging. With the advancement of technology, it has become easier to conduct surveys using

93 affordable, high-quality equipment like night vision and thermal cameras; and in the last 10 years

94 a number of behavioral studies have been conducted on volant species at tall structures (e.g.,

95 Long, Flint \& Lepper 2011; Mirzaei et al. 2012; McAlexander 2013; Watson, Keren \& Davies

96 2018). For example, from behavioral surveys conducted at wind turbines, Cryan et al. (2014)

97 suggested that bat behavior around these structures was similar to behavior observed at tall trees

98 where bats are searching for roosts, potential mates, and insect prey. However, the use of such

99 technology in this field of study is still relatively new and there are no standardized protocols or

100 even recommended guidelines available, making quantitative comparisons between different

101 studies difficult. For example, while some studies have opted to use thermal cameras (e.g., Cryan

102 et al. 2014), others have used night vision (McAlexander 2013), and we currently do not know

103 the extent to which these different technologies may vary in the number and quality of

104 behavioral observations recorded. 
106 for assessing the behavior of bats at tall structures. We 1) created a customized classification key

107 to identify bats from other flying animals and characterize specific behaviors; 2) compared the

108 effectiveness of currently available technologies (night vision and thermal cameras) for

109 surveying bats; and 3) assessed optimal thermal camera placement in proximity to a tall

110 structure. Based on the findings of our study, we aim to make recommendations on survey

111 methods that can be widely implemented when investigating wildlife interactions with tall

112 structures.

\section{Methods}

\section{Study site}

115 We conducted our study at a utility-scale wind energy facility that has been operational since

1162008 in north-central Texas, USA (N 334' $53.538^{\prime \prime}$, W 97²4'18.186”). This facility consists of

117 75 1.5-MW General Electric wind turbines comprising an $80 \mathrm{~m}$ tower, a $2 \mathrm{~m}$ nacelle, and $340 \mathrm{~m}$

118 blades $($ maximum height $=122 \mathrm{~m})$. The $48 \mathrm{~km}^{2}$ wind resource area encompasses a matrix of

119 cattle pastures, hayfields, cultivated fields, and scrub woodland. Surveys conducted from 2009 to

1202013 identified 7 bat species at this site, including 6 species found in post-construction fatality

121 monitoring surveys (eastern red (Lasiurus borealis), hoary (Lasiurus cinereus), silver-haired bat

122 (Lasionycteris noctivagans), tri-colored (Perimyotis subflavus), evening (Nycticeius humeralis),

123 and Mexican free-tailed (Tadarida brasiliensis) bats), and one additional species, the canyon bat

124 (Parastrellus herperus), that was recorded in acoustic surveys (Bennett \& Hale 2014; Lindsey

125 2017; Bennett \& Hale 2018). Furthermore, bats have been observed in close proximity to the

126 wind turbine towers at this facility (McAlexander 2013). We, therefore, deemed the facility to be

127 an appropriate location to survey bat behavior and activity at wind turbine towers. 


\section{Behavioral observation surveys}

129 In 2016 during the fall bat migratory period from July to mid-August (Krauel 2013; Bennett \&

130 Hale 2018), we conducted a series of behavioral surveys to explore bat interactions with wind

131 turbine towers. We elected to focus our surveys on the tower monopoles rather than the entire

132 rotor swept zone, as current literature has suggested that the towers themselves provide resources

133 for bats (Long et al. 2011; McAlexander 2013; Jameson and Willis 2014; Bennett et al. 2017,

134 Foo et al. 2017). For these surveys, six turbines were selected that had high levels of bat fatalities

135 recorded in the aforementioned fatality monitoring surveys (Bennett \& Hale 2014; Bennett \&

136 Hale 2018).

137 At 1-2 turbine sites per night, we conducted surveys to record bat activity in proximity to

138 the turbine tower. For this, we investigated the effectiveness of 2 currently available technologies

139 previously used to study volant species: night vision (Warren et al. 2006; Fuller, Hammond \&

140 Tomasi 2012) and thermal cameras (Blowers et al. 2015; Matzner, Cullinan \& Duberstein 2015;

141 Hayman et al. 2017). Night vision technology functions by taking all the available light,

142 including infrared light, and amplifies it to allow the user to see in the dark. In contrast, thermal

143 cameras use differences in heat energy emitted by all objects (thermal radiation) making them

144 visually distinguishable. For example, as warm-bodied animals tend to have higher temperatures

145 than the surrounding environment, they become visible even when they are in the dark or

146 otherwise hidden from view. Using both technologies simultaneously, we then estimated the

147 number of flying animals observed, determined which kinds of flying animals could be identified

148 (e.g., bird, bat, moth, etc.), and categorized specific bat behaviors that were readily discernable

149 with each technology type.

150 A night vision setup consisted of an ATN NVM14 night vision scope attached to Sony

151 HDR-PJ790 video camcorder and placed on a Manfrotto MT055XPRO3 tripod, and 2 ATN

Peer) reviewing PDF | (2019:05:37412:2:0:NEW 13 Dec 2019) 
152 Super Long Range Infrared Illuminator IR450 lights mounted atop VELBON EF tripods. For the

153 thermal setup, we used an Axis Q1932-E 19MM thermal camera mounted on a Manfrotto

154 MT055XPRO3 tripod, connected via an Ethernet cable and a Netgear ProSAFE 8-Port Fast

155 Ethernet PoE Switch to an HP Compaq 8510w laptop with Axis Companion software (version

156 3.20.010, Axis Communications AB, Lund, Sweden), and powered by a 12 Volt 35 Amp

157 automotive battery through a Cen-Tech Power Inverter.

158 From previous behavioral surveys using night vision at our site (2012 and 2013), we

159 established that the optimal distance for identifying flying animals and their behavior using this

160 technology was $2 \mathrm{~m}$ from the base of the tower (Fig. 1; McAlexander 2013). Thus, as farther

161 deployment distances were known to decrease detectability of flying animals, we opted to keep

162 the night vision setups at this $2 \mathrm{~m}$ distance throughout this study. Furthermore, as bat activity can

163 differ between the windward and leeward sides of wind turbines, we placed a night vision setup

164 on either side of each survey tower (Cryan et al. 2014). We angled the field-of-view of both

165 setups upward to capture the full length of the monopole (i.e., from $\sim 10 \mathrm{~m}$ above the gravel pad

166 to the lower surface of the nacelle hub $\sim 80 \mathrm{~m}$ above ground level). We also placed the 2 infrared

167 lights $\sim 1 \mathrm{~m}$ from either side of each night vision setup, angling them upward to illuminate the 168 tower surface.

169 For the thermal setups, there were currently no definitive recommendations regarding 170 placement of equipment. Previous research using thermal cameras at wind turbines has varied 171 camera placement from between 25 and $80 \mathrm{~m}$ from the base of the structure (Horn, Arnett \&

172 Kunz 2008; Cryan et al. 2014). Thus, we sought to establish a thermal camera location that could

173 effectively be used to survey the interactions of volant species with tall structures. For this, we

174 incrementally tested a variety of distances to identify the camera location that yielded the highest 
175 number of observed flying animals per hour, and not only optimized our ability to identify these

176 animals (e.g., bird, bat, moth, etc.), but also allowed for specific behaviors to be distinguished.

177 We conducted a series of surveys with thermal cameras placed $2 \mathrm{~m}, 25 \mathrm{~m}, 50 \mathrm{~m}$, and 95

$178 \mathrm{~m}$ from the base of the leeward side of wind turbine towers (Fig. 1). We selected the leeward side

179 as research has shown higher bat activity relative to the windward side of wind turbine towers

180 (Cryan et al. 2014). For each distance tested, we adjusted the angle of the camera to maximize

181 tower coverage from $\sim 10 \mathrm{~m}$ above the ground to the base of the nacelle ( $\sim 80 \mathrm{~m}$ above ground

182 level) within the field-of-view. Note that the placement at $95 \mathrm{~m}$ from the base was tested because

183 it captured the entire turbine, from the ground up to the top of the rotor swept zone, within the

184 field-of-view.

185 During all surveys, we also used an ultrasonic acoustic detector to record species-specific

186 bat activity around the towers. The acoustic recording equipment setup comprised an AR-125-

187 EXT Ultrasonic Receiver and an iFR IV Integrated Field Recorder System from Binary Acoustic

188 Technology, LLC with the microphone mounted atop a standard tripod. We pre-set the detectors

189 to trigger at frequencies between 20 and $110 \mathrm{kHz}$ at a gain threshold of $12.0 \mathrm{~dB}$, trigger volume

190 of $12.0 \mathrm{~dB}$, and a duration of 4.0 seconds. Sound files were recorded as 4 -second standard .wav

191 files. Note that the detection range was limited to a maximum of $45 \mathrm{~m}$ (frequency-dependent).

192 These detectors were placed at the base of each turbine alongside the night vision set-up on the

193 leeward side of the turbine (Fig. 1). Ultrasonic detectors were turned on prior to starting the

194 behavioral surveys and turned off when surveys were completed each night.

195 A survey night began 20 minutes after sunset and continued for up to 200 minutes to

196 encompass the primary bat activity period (Hayes 1997; Baerwald \& Barclay 2011;

197 McAlexander 2013). Within this time, we conducted a series of 1210 -min trials (this trial length 
198 was selected to ensure the equipment was working during the surveys and allowed us to process

199 the recorded footage more efficiently) and ensured that all cameras were turned on and off in

200 sync. We used visual cues (hand swipes) to synchronize the footage in the processing stage. Note

201 that night vision scopes were not used for the first trial as they would not function during low

202 light levels. Prior to each trial, we recorded the temperature $\left({ }^{\circ} \mathrm{C}\right)$, wind speed $(\mathrm{km} / \mathrm{hr})$, and gust

203 speed $(\mathrm{km} / \mathrm{hr})$ and did not conduct trials if temperatures were $<5^{\circ} \mathrm{C}$, wind speeds were $>24$

$204 \mathrm{~km} / \mathrm{hr}$, wind gusts were $>32 \mathrm{~km} / \mathrm{hr}$, or if it was raining.

205 We processed all trial recordings using Studiocode video analysis software (version 5,

206 Studiocode Business Group, Sydney, AU). In this software, we marked and timestamped any

207 flying animals $\geq 8 \mathrm{~cm}$ (i.e., the length of the long axis of the smallest bat locally recorded, the tri-

208 colored bat; Ammerman et al. 2012) that were observed within $2 \mathrm{~m}$ of the turbine tower. For the

209 latter, we superimposed an 'observation zone' onto each video in Studiocode that was scaled

210 using features, such as known flange and nacelle widths, from the wind turbine towers. By

211 recording flying animals within this observation zone only, we kept the sampling area within the

212 field-of-view consistent among the 4 different thermal camera distances we tested. We defined a

213 'bat' as any animal that had a silhouette resembling the body shape of a bat (i.e., visible head

214 with ears, robust body, tapering wings serrated along the posterior edge, potentially with finger

215 bones visible in the patagium; Fig. 2A-B). We defined a 'non-bat' as any animal with

216 characteristics that a bat would not have (e.g., two pairs of wings, wings joined on the upper half

217 of the body only, or thin bodies which are characteristic of some large insect species; presence of

218 a beak, finger-like projections towards the ends of the wings, or long feathered tail which are

219 characteristics of birds; Fig. 2C-D). Lastly, we defined an unidentifiable animal as any animal

220 that had no defining characteristics visible (Fig. 2E-F). As the goal of our study was to maximize 
221 flying animal identification, an effective survey method would minimize the number of animals 222 classified as 'undefined animals'.

223 To understand how bats were interacting with tall structures, one aspect of our survey

224 method was to recognize specific behaviors. Thus, we defined the following 9 distinct bat

225 behaviors: passing - when a bat flew across the field-of-view in a relatively straight flight path

226 ( $\leq 1$ turn); reversing - when a bat entered the field-of-view and turned back the way it came

227 without passing the tower; looping - when a bat turned around at or after passing in front or

228 behind the tower and returned back the way it came; foraging - when a bat flew in a zig-zag

229 pattern with $\geq 2$ changes in direction (i.e., turns); chasing - when a bat was closely followed by

230 another bat; skimming - when a bat flew low over the tower, with its body parallel to the surface

231 potentially making contact; sweeping - when a bat flew low over the tower and made contact

232 with an outstretched wing tip; colliding - when a bat flew directly into the tower; and gleaning -

233 when a bat hovered briefly over the surface of the tower before making contact with the surface

234 (i.e., to potentially grab a prey item) before flying away. For the latter 4 behaviors, the

235 reflections of bats in the turbine surface were used to confirm contact. We then classified the

236 behaviors exhibited, where possible, by every 'bat' observed and indistinguishable behaviors

237 (i.e., less than $1 \mathrm{sec}$ appearance in a corner of the field-of-view, or a lack of image clarity) were

238 classified as unknown. As our study focused on the identification of bat behaviors in proximity to

239 tower surfaces, we combined behaviors into 3 categories for the following analyses: contact (all

240 behaviors in which a bat appeared to touch the turbine tower surface, including skimming,

241 sweeping, colliding, and gleaning), unknown, and all other behaviors (including passing,

242 reversing, looping, foraging, and chasing). As our survey goal was to facilitate behavioral

243 identification, an effective method would minimize the number of unknown behaviors. Note that 
244 night vision and thermal camera recordings were scored separately to avoid bias and all footage

245 was reviewed and scored independently by 2 separate individuals.

246 To determine whether flying animal detectability, identification, and behavioral

247 classification differed between night vision and thermal cameras placed at a range of distances

248 from the turbine tower base, we calculated the difference in the number of flying animals, the

249 number of bats and non-bats, and the number of classified behaviors detected using night vision

250 and thermal cameras for each turbine night ( $\mathrm{n}=21$ turbine nights with $\geq 1$ flying animal detected

251 during the full 120-minute survey period). For each response variable, we used a one-way

252 ANOVA to compare the performance of night vision and thermal cameras. Due to unequal

253 variances among distance categories for the thermal cameras, we pooled the locations as near

254 (2m from the turbine tower base: $\mathrm{n}=12$ turbine nights) and far $(25,50$, and $95 \mathrm{~m}: \mathrm{n}=9$ turbine

255 nights) in the analyses. To evaluate the effect of distance from the turbine tower on the

256 performance of thermal cameras, we used the number of observations (flying animals, bats and

257 non-bats, and classified behaviors) as our response variable and distance as our explanatory

258 variable ( $\mathrm{n}=21$ turbine nights with $\geq 1$ flying animal detected during the full 120 -minute survey

259 period). Due to unequal variances among distances, we again pooled the far locations and used a

260 Welch's t-test to compare the mean number of observations for thermal cameras placed near $(2 \mathrm{~m}$

261 from the turbine tower base: $\mathrm{n}=12$ turbine nights $)$ and far $(25,50$, and $95 \mathrm{~m}: \mathrm{n}=9$ turbine

262 nights) from the wind turbine towers. For all statistical analyses, we used Minitab software

263 (version 18, Pennsylvania, USA) with $\alpha=0.05$.

\section{Results}

265 From 1 July to 10 August 2016, we detected 551 flying animals in night vision and thermal 266 camera surveys on 28 turbine nights (Table 1). On 7 of these turbine nights, not one flying 
267 animal was recorded. During the remaining survey nights, we recorded 194 bat acoustic calls,

268 from which we identified: Lasiurus borealis $(n=103)$; Lasiurus cinereus $(n=1)$; Lasionycteris

269 noctivagans $(n=7) ;$ P. subflavus $(n=39)$; and $N$. humeralis $(n=44)$.

270 In the first surveys we conducted, thermal cameras were placed $95 \mathrm{~m}$ from the tower base

271 ( $\mathrm{n}=12$ turbine nights with $\geq 1$ flying animal). At this distance, we found that flying animals

272 were indistinguishable from the horizon because they were saturated by the infrared radiation

273 signature it generated. In contrast, we noted that these flying animals remained visible in night

274 vision recordings (setup located $2 \mathrm{~m}$ from tower base) and we were able to identify distinct bat

275 behaviors, including close contact with the turbine tower. We then placed thermal cameras

276 alongside the night vision setup $2 \mathrm{~m}$ from the base of the turbine tower and observed 50\% more

277 flying animals in the thermal camera footage compared to the night vision $(\mathrm{n}=12$ turbine nights

278 with $\geq 1$ flying animal). Moreover, $>200 \%$ more bats were identified in the thermal camera

279 footage in comparison to the night vision (see Table 1). With regards to behavior, we found that $280>200 \%$ more behaviors were readily identified in thermal camera footage compared to the night

281 vision and we were able to distinguish contact behaviors in the thermal camera footage (see 282 Table 1).

283 When testing thermal cameras at $50 \mathrm{~m}$ and $25 \mathrm{~m}$ (in that order) from the turbine base, we 284 opted to keep a second thermal camera $2 \mathrm{~m}$ from the base for an additional comparison as we 285 knew that bats could be readily identifiable at this distance $(\mathrm{n}=2$ turbine nights for each 286 distance) When thermal cameras were placed $50 \mathrm{~m}$ and $25 \mathrm{~m}$ from the tower base, we detected $287>60 \%$ fewer flying animals compared to either the thermal cameras or night vision at the $2 \mathrm{~m}$ 288 distance (see Table 1). Moreover, $>80 \%$ and $>40 \%$ fewer bats were identified in the thermal 289 cameras at $50 \mathrm{~m}$ and $25 \mathrm{~m}$, respectively, compared to the thermal camera footage recorded at $2 \mathrm{~m}$ 
290 (see Table 1). Again, at the $2 \mathrm{~m}$ distance thermal cameras appeared to perform better than night 291 vision during the surveys. Lastly, we were able to identify $80 \%$ fewer behaviors in thermal 292 cameras at $2 \mathrm{~m}$ compared to $50 \mathrm{~m}$, although identification was similar at $25 \mathrm{~m}$ and $2 \mathrm{~m}$ (see

293 Table 1). Note that no contact behaviors were observed in any footage recorded during these 294 surveys.

295 We found a significant difference in the number of flying animals detected between night 296 vision and thermal cameras when the thermal cameras were placed near and far from the turbine 297 tower base (Fig. 3A; $\mathrm{F}_{1,19}=33.07, P<0.001$ ). With thermal cameras at $2 \mathrm{~m}$ from the tower 298 base, we detected significantly fewer flying animals using night vision technology (95\% CI: -9.6, 299 -3.5). Yet with the thermal cameras at farther distances, we detected significantly more flying 300 animals using night vision technology (95\% CI: 2.7, 9.8). For the number of bats and non-bats 301 detected, we also found a significant difference between technology types (Fig. 3B; $\mathrm{F}_{1,19}=$ $30249.24, P<0.001)$. With thermal cameras at $2 \mathrm{~m}$ from the tower base, we detected significantly 303 fewer bats and non-bats using night vision technology (95\% CI: -10.2, -5.4), whereas at far 304 distances we detected significantly more bats and non-bats with night vision technology (95\% 305 CI: 1.8, 7.3). And finally, for the number of classified behaviors, we also found a significant 306 difference between technology types (Fig. 3C; $\mathrm{F}_{1,19}=26.89, P<0.001$ ). With thermal cameras

307 at $2 \mathrm{~m}$ from the tower base, we classified significantly fewer behaviors using night vision 308 technology (95\% CI: $-5.6,-2.0)$, whereas at far distances we classified significantly more 309 behaviors with night vision technology $(95 \%$ CI: 0.92, 5.1).

310 When comparing just thermal cameras, we also found a significant difference in 311 performance that varied with distance from the turbine tower base. For the number of flying 312 animals, detections using thermal cameras were significantly higher near turbine towers 
313 compared to farther away (Fig. 4A; Welch's t-test: $\mathrm{t}_{14}=6.05, P<0.001 ; 95 \% \mathrm{CI}: 11.1,23.3$ ).

314 For the number of bats and non-bats, detections were also significantly higher near turbine

315 towers compared to farther away (Fig. 4B; Welch's t-test: $\mathrm{t}_{12}=7.18, P<0.001 ; 95 \% \mathrm{CI}$ : 9.9,

316 18.6). And finally, for the number of classified behaviors, these were also significantly higher

317 near turbine towers compared to farther away (Fig. 4C; Welch's t-test: $\mathrm{t}_{18}=4.30, P<0.001 ; 95 \%$

318 CI: 2.3, 6.8).

\section{Discussion}

320 Detectability, identification, and behavioral classification of flying animals varied between night

321 vision and thermal camera recordings, and between thermal cameras positioned $2 \mathrm{~m}, 25 \mathrm{~m}, 50 \mathrm{~m}$,

322 and $95 \mathrm{~m}$ from the base of the wind turbine towers in our study. These findings indicate that

323 behavioral observation surveys differing in their set-up could potentially yield different results.

324 More specifically, our study revealed that data collected could vary due to limitations associated

325 with the technology used. For example, flying animals and behaviors in front of tower surfaces

326 were more readily identified using night vision technology; however, animals approaching the

327 tower were virtually indistinguishable from the night sky (Fig. 5A). This limitation made it more

328 challenging to detect flying animals approaching the towers and identify specific behaviors,

329 unless the latter occurred directly in front of the tower (Fig. 5B-C).

330 A similar detection limitation occurred with the thermal cameras, albeit to a lesser extent,

331 as approaching animals could not be clearly seen in the lower half of the field-of-view at

332 distances of $25 \mathrm{~m}, 50 \mathrm{~m}$, and $95 \mathrm{~m}$, due to an infrared radiation signature generated by the

333 horizon. Moreover, while these distances provided a larger field-of-view in which flying animals

334 approaching the wind turbine towers were observed earlier (potentially increasing detection),

335 there were consequences in terms of resolution, subsequently reducing the identification of 
336 flying animals and behaviors effectively. For example, our ability to classify bat behavior in

337 close proximity to the turbine towers was reduced at $25 \mathrm{~m}$ distances compared with $2 \mathrm{~m}$

338 distances, and it was difficult to detect approaching flying animals, let alone identify them, at the

$33995 \mathrm{~m}$ distance. At the $2 \mathrm{~m}$ distance, as the thermal cameras were angled up toward the wind

340 turbine tower, there was no horizon in the field-of-view. Subsequently, approaching flying

341 animals and behaviors were more visible and identifiable, even though the area in which

342 approaching bats could be observed was limited to $<1 \mathrm{~m}$ toward the base of the turbine tower to

$343 \sim 40 \mathrm{~m}$ out from the top of the tower monopole beneath the nacelle (Fig. 5D). Another drawback

344 with the use of thermal cameras was that the surfaces of the monopole and nacelle also generated

345 an infrared radiation signature that tended to obscure visibility when animals passed directly in

346 front of them (Fig. 5E-F). Note that while it was not impossible to identify specific behaviors

347 within these areas of the turbine, it did make scoring videos more challenging (reduced

348 confidence) and time consuming.

349 In summary, our study revealed contrasting advantages and disadvantages in using both

350 of the technologies tested. Ultimately, set-up selection depends on the objective of a study. If

351 surveys are intended to record presence, activity patterns, and abundance of bats or other similar-

352 sized flying animals such as small birds, then thermal cameras at distances of $25 \mathrm{~m}$ from the

353 turbine would maximize data collection. For example, comparing the night vision and thermal

354 cameras observations of the flying animals, $34 \%$ were detected with thermal cameras and not

355 with night vision technology, whereas only $1 \%$ were detected with night vision technology and

356 not with thermal cameras. Moreover, at this distance both night vision and thermal cameras can

357 be readily angled to incorporate different areas of the turbine in their field-of-view, whether it be

358 the entire rotor swept zone or the majority of the turbine monopole and nacelle. Studies, such as 
359 Roemer et al. (2017), that set out to determine rates of bat or bird collisions with wind turbines,

360 whether bat activity can be used to predict fatality, or monitor the effectiveness of operational

361 minimization strategies, would likely benefit from using thermal cameras at $25 \mathrm{~m}$ from the wind

362 turbine base.

363 In comparison, if the goal of a study is to specifically explore why bats are coming into

364 contact with wind turbines or other tall structures, then a set-up $2 \mathrm{~m}$ from the base of the

365 structure would optimize the resolution needed to effectively conduct behavioral observation

366 surveys. Studies, such as Jameson and Willis (2014), that explore whether bats are attracted to

367 tall structures for social interactions and foraging, mating, and roosting opportunities, could

368 optimize data collection with the use of thermal cameras at a $2 \mathrm{~m}$ distance. Nevertheless, with the

369 aforementioned limitations of both night vision and thermal cameras at $2 \mathrm{~m}$, a study that either

370 uses one or the other technology could lead to variations in animal identification and behavioral

371 classification with the potential to bias the results of the study. For example, among the flying

372 animals recorded in both the night vision and thermal cameras, $87 \%$ were identified as bats or

373 non-bats with thermal cameras and $60 \%$ with night vision technology. Similarly, $66 \%$ of

374 behaviors were classified with thermal cameras and 31\% with night vision technology. Thus, our

375 findings indicated that using the two technologies in combination with one another yields more

376 reliable results, with thermal cameras optimizing our ability to detect approaching animals and

377 night vision enhancing and making it much easier to identify animals and classify behavior at the

378 wind turbine tower surfaces.

379 We also acknowledge that the shortcomings of thermal cameras in our study may have

380 been exacerbated by high ambient temperatures at our site; other study locations with lower

381 ambient temperature may not experience such radiation-related issues. Regardless, in areas with 
382 similar climates to our study site, we certainly recommend the combined technology setup. We

383 also consider that these recommendations are relevant to any survey of flying animals conducted

384 at tall metal structures.

385 Another consideration is the placement and number of night vision or thermal camera set-

386 ups for the surveys. If economically feasible, we recommend that set-ups are positioned on more

387 than one side of the structure to effectively detect flying animal presence and capture interactions

388 around the entire structure. However, as previous studies at wind turbines have shown that the

389 majority of activity occurs on the leeward side of the turbine (Cryan et al. 2014; Hein \&

390 Schirmacher 2016), in these instances, one set-up may be effective. The challenge with using

391 multiple set-ups with overlapping field-of-views is to avoid the duplication of observations.

392 Viewing and scoring footage from multiple fields-of-view simultaneously would reduce the

393 occurrence of this type of data replication happening.

394 In addition, for all surveys at wind turbines and other tall structures, we recommend the

395 creation of an object identification key to allow comparable and repeatable flying animal

396 identification. Note that our key was customized for our taxonomic group of interest, survey

397 timing (e.g., day or night), and study site; we therefore recommend that keys are customized and

398 validated for specific surveys. For example, the key created in our study could easily be modified

399 for bird species that may be flying near wind turbines at night, and even used for the bigger-

400 bodied invertebrates such as moths, dragonflies, and grasshoppers.

401 Of course, as technology is quickly advancing and continues to improve with new models

402 becoming commercially available each year, the issues highlighted in our study may become less

403 problematic. Nevertheless, if we are to understand why, for example, bats are coming into

404 contact with wind turbines, it is crucial to compare and collate data from different studies, past 
405 and present. By doing so, we can uncover those patterns in activity and bat behavior at regional,

406 national, and even global scales, which in turn may help inform effective mitigation for reducing

407 fatalities in wind energy facilities. Thus, it is important that we acknowledge the capabilities and

408 limitations of the technology, such as resolution, used in each study, so that we can make

409 appropriate comparisons.

\section{Conclusion}

411 As the construction of anthropogenic structures continues to modify air spaces, behavioral

412 surveys will only become more important (Cousins et al. 2012; Arnett \& Baerwald 2013;

413 Vasenev et al. 2018). Furthermore, existing structures could be modified and improved (i.e.,

414 increased height of towers, length of wind turbine blades, etc.), thus understanding how these

415 changes could impact wildlife should be considered (Thomsen 2009). For these future studies,

416 we have made recommendations to standardize surveys that would allow for comparison

417 between different studies, structure types, and sites, thereby increasing our ability to effectively

418 inform mitigation strategies to alleviate anthropogenic effects to wildlife. 


\section{Acknowledgements}

421 We would like to thank NextEra Energy Resources and the TCU Department of Environmental

422 Science for their support. Additionally, we express gratitude to all technicians who worked on

423 this project: Ryan Conley, Martin McQueen, Cole Lindsey, and Matt Paulsen; and we would also

424 like to thank the following reviewers: Dr. Michael Slattery, Becky Johnson, Kathryn Smith, 425 Martin McQueen, and Alyssa Austin. 


\section{References}

428

429

430

431

432

433

434

435

436

437

438

439

440

441

442

443

444

445

446

447

448

449

450

451

452

453

454

455

456

457

458

459

460

461

462

463

464

465

466

467

468

Alerstam T. 1979. Wind as selective agent in bird migration. Ornis Scandinavica (Scandinavian Journal of Ornithology) 10:76-93 DOI 10.2307/3676347

Ammerman LK, Hice CL, Schmidly DJ. 2012. Bats of Texas. College Station: Texas A\&M University Press.

Arnett EB, and Baerwald EF. 2013. Impacts of wind energy development on bats: implications for conservation. In: Pederson RAASC, ed. Bat Evolution, Ecology, and Conservation. New York: Springer Science+Business Media, 435-456.

Arnett EB, Baerwald EF, Matthews F, Rodrigues L, Rodriguez-Duran A, Rydell J, VillegasPatraca R, and Voigt CC. 2016. Impacts of wind energy development on bats: a global perspective. In: Kingston CCVT, editor. Bats in the Anthropocene: Conservation of Bats in a Changing World. Springer International Publishing. p 295-323.

Arnett EB, Hein CD, Schirmacher MR, Huso MMP, and Szewczak JM. 2013. Evaluating the effectiveness of an ultrasonic acoustic deterrent for reducing bat fatalities at wind turbines. PLOS ONE 8:e65794 DOI 10.1371/journal.pone.0065794

Arnett EB, Huso MM, Schirmacher MR, and Hayes JP. 2011. Altering turbine speed reduces bat mortality at wind-energy facilities. Frontiers in Ecology and the Environment 9:209-214 DOI 10.1890/100103

Avery M, Springer PF, and Cassel JF. 1976. The effects of a tall tower on nocturnal bird migration: a portable ceilometer study. The Auk 93:281-291.

Avian Power Line Interaction Committee A. 2006. Suggested Practices for Avian Protection on Power Lines: The State of the Art in 2006. Washington, D.C. and Sacramento, California: Edison Electric Institute, APLIC, and the California Energy Commission.

Avila-Flores R, and Fenton MB. 2005. Use of spatial features by foraging insectivorous bats in a large urban landscape. Journal of Mammalogy 86:1193-1204 DOI 10.1644/04-MAMMA-085R 1.1

Baerwald EF, and Barclay RMR. 2011. Patterns of activity and fatality of migratory bats at a wind energy facility in Alberta, Canada. Journal of Wildlife Management 75:1103-1114 DOI 10.1002/jwmg. 147

Balotari-Chiebao F, Brommer JE, Niinimäki T, and Laaksonen T. 2016. Proximity to windpower plants reduces the breeding success of the white-tailed eagle. Animal Conservation 19:265-272 DOI 10.1111/acv.12238

Bennett V, and Hale A. 2018. Resource availability may not be a useful predictor of migratory bat fatalities or activity at wind turbines. Diversity 10:44.

Bennett VJ, and Hale AM. 2014. Red aviation lights on wind turbines do not increase bat-turbine collisions. Animal Conservation 17:354-358 DOI 10.1111/acv.12102

Bennett VJ, Hale AM, and Williams DA. 2017. When the excrement hits the fan: fecal surveys reveal species-specific bat activity at wind turbines. Mammalian Biology 87:125-129 DOI 10.1016/j.mambio.2017.08.003.

Bernardino J, Bevanger K, Barrientos R, Dwyer JF, Marques AT, Martins RC, Shaw JM, Silva JP, and Moreira F. 2018. Bird collisions with power lines: state of the art and priority areas for research. Biological Conservation 222:1-13 DOI 10.1016/j.biocon.2018.02.029

Peer) reviewing PDF | (2019:05:37412:2:0:NEW 13 Dec 2019) 
469

470

471

472

473

474

475

476

477

478

479

480

481

482

483

484

485

486

487

488

489

490

491

492

493

494

495

496

497

498

499

500

501

502

503

504

505

506

507

508

509

510

511

512

513

514
Blowers Z, Kloepper L, Linnenschmidt M, and Simmons J. 2015. Population estimates and emergence trends of Mexican free-tailed bats using image processing tools. Bat Research News 56:71.

Cousins RA, Battley PF, Gartrell BD, and Powlesland RG. 2012. Impact injuries and probability of survival in a large semiurban endemic pigeon in New Zealand, Hemiphaga novaeseelandiae. Journal of Wildlife Diseases 48:567-574 DOI 10.7589/0090-355848.3.567

Crawford RL, and Wilson Baker W. 1981. Bats killed at a North Florida television tower: a 25year record. Journal of Mammalogy 62:651-652 DOI 10.2307/1380421

Cryan PM, Gorresen PM, Hein CD, Schirmacher MR, Diehl RH, Huso MM, Hayman DTS, Fricker PD, Bonaccorso FJ, Johnson DH, Heist K, and Dalton DC. 2014. Behavior of bats at wind turbines. Proceedings of the National Academy of Sciences 111:1512615131 DOI 10.1073/pnas.1406672111.

Cryan PM, Barclay RMR. 2009. Causes of bat fatalities at wind turbines: hypotheses and predictions. Journal of Mammalogy 90:1330:1340 DOI 10.1644/09-MAMM-S-076R1.1.

Dahl EL, Bevanger K, Nygård T, Røskaft E, and Stokke BG. 2012. Reduced breeding success in white-tailed eagles at Smøla windfarm, western Norway, is caused by mortality and displacement. Biological Conservation 145:79-85 DOI 10.1016/j.biocon.2011.10.012

de Lucas M, Ferrer M, Bechard MJ, and Muñoz AR. 2012. Griffon vulture mortality at wind farms in southern Spain: distribution of fatalities and active mitigation measures.

Biological Conservation 147:184-189. https://doi.org/10.1016/j.biocon.2011.12.029

Diehl RH. 2013. The airspace is habitat. Trends in Ecology \& Evolution 28:377-379 DOI 10.1016/j.tree.2013.02.015

Dwyer JF, Pandey AK, McHale LA, and Harness RE. 2019. Near-ultraviolet light reduced Sandhill Crane collisions with a power line by 98\%. The Condor 121:1-10 DOI 10.1093/condor/duz008

Erickson WP, Wolfe MM, Bay KJ, Johnson DH, and Gehring JL. 2014. A comprehensive analysis of small-passerine fatalities from collision with turbines at wind energy facilities. PLOS ONE 9(9): e107491 DOI 10.1371/journal.pone.0107491

Erickson WPJ, Gregory, D.; Young, David P. Jr. . 2005. A summary and comparison of bird mortality from anthropogenic causes with an emphasis on collisions. In: Ralph CJR, Terrell D., editor. Bird Conservation Implementation and Integration in the Americas: Third International Partners in Flight Conference. Asilomar, California: U.S. Dept. of Agriculture, Forest Service, Pacific Southwest Research Station. p 1029-1042.

Foo CF, Bennett VJ, Hale AM, Korstian JM, Schildt AJ, and Williams DA. 2017. Increasing evidence that bats actively forage at wind turbines. PeerJ 5:e3985; DOI 10.7717/peerj.3985

Frick WF, Baerwald EF, Pollock JF, Barclay RMR, Szymanski JA, Weller TJ, Russell AL, Loeb SC, Medellin RA, and McGuire LP. 2017. Fatalities at wind turbines may threaten population viability of a migratory bat. Biological Conservation 209:172-177 DOI 10.1016/j.biocon.2017.02.023

Fuller B, Hammond S, and Tomasi T. 2012. Infrared video population counts of Ozark big-eared bat maternity and limited-use sites. Bat Research News 53:80.

Gehring J, Kerlinger P, and Manville AM. 2009. Communication towers, lights, and birds: successful methods of reducing the frequency of avian collisions. Ecological Applications 19:505-514 DOI 10.1890/07-1708.1

Peer] reviewing PDF | (2019:05:37412:2:0:NEW 13 Dec 2019) 
515 Goller B, Blackwell BF, DeVault TL, Baumhardt PE, and Fernández-Juricic E. 2018. Assessing

516 bird avoidance of high-contrast lights using a choice test approach: implications for

517 reducing human-induced avian mortality. Peerj 6:e5404 DOI 10.7717/peerj.5404

518 Hayes JP. 1997. Temporal variation in activity of bats and the design of echolocation-monitoring

519 studies. Journal of Mammalogy 78:514-524 DOI 10.2307/1382902

520

521

522

523

524

525

526

527

528

529

530

531

532

533

534

535

536

537

538

539

540

541

542

543

544

545

546

547

548

549

550

551

552

553

554

555

556

557

558

559

Hayes MA. 2013. Bats Killed in Large Numbers at United States Wind Energy Facilities. Bioscience 63:975-979 DOI 10.1525/bio.2013.63.12.10

Hayes MA, Hooton LA, Gilland KL, Grandgent C, Smith RL, Lindsay SR, Collins JD, Schumacher SM, Rabie PA, Gruver JC, and Goodrich-Mahoney J. 2019. A smart curtailment approach for reducing bat fatalities and curtailment time at wind energy facilities. Ecological Applications 29(4):e01881 DOI 10.1002/eap.1881

Hayman DTS, Cryan PM, Fricker PD, and Dannemiller NG. 2017. Long-term video surveillance and automated analyses reveal arousal patterns in groups of hibernating bats. Methods in Ecology and Evolution 8:1813-1821. DOI 10.1111/2041-210x.12823

Hein CD, and Schirmacher MR. 2016. Impact of wind energy on bats: a summary of our current knowledge. Human-Wildlife Interactions 10.

Horn JW, Arnett EB, and Kunz TH. 2008. Behavioral responses of bats to operating wind turbines. Journal of Wildlife Management 72:123-132 DOI 10.2193/2006-465

Jameson JW, and Willis CKR. 2014. Activity of tree bats at anthropogenic tall structures: implications for mortality of bats at wind turbines. Animal Behaviour 97:145-152 DOI 10.1016/j.anbehav.2014.09.003

Krauel JJM, G. F. 2013. Recent advances in bat migration research. In: Pederson RAASC, ed. Bat Evolution, Ecology, and Conservation. New York: Springer Science+Business Media, 293-313.

Lindsey CT. 2017. Assessing changes in bat activity in response to an acoustic deterrent: implications for decreasing bat fatalities at wind facilities. Biology Masters of Science. Texas Christian University.

Long CV, Flint JA, and Lepper PA. 2011. Insect attraction to wind turbines: does colour play a role? European Journal of Wildlife Research 57:323-331.

Longcore T, Rich C, Mineau P, MacDonald B, Bert DG, Sullivan LM, Mutrie E, Gauthreaux SA, Jr., Avery ML, Crawford RL, Manville AM, II, Travis ER, and Drake D. 2012. An estimate of avian mortality at communication towers in the United States and Canada. PLOS ONE 7:e34025 DOI 10.1371/journal.pone.0034025

Loss SR, Will T, and Marra PP. 2013. Estimates of bird collision mortality at wind facilities in the contiguous United States. Biological Conservation 168:201-209 DOI 10.1016/j.biocon.2013.10.007

Loss SR, Will T, and Marra PP. 2015. Direct mortality of birds from anthropogenic causes. Annual Review of Ecology, Evolution, and Systematics 46:99-120. 10.1146/annurevecolsys-112414-054133

Lu X, McElroy MB, and Kiviluoma J. 2009. Global potential for wind-generated electricity. Proceedings of the National Academy of Sciences 106:10933-10938. 10.1073/pnas.0904101106

Martin CM, Arnett EB, Stevens RD, and Wallace MC. 2017. Reducing bat fatalities at wind facilities while improving the economic efficiency of operational mitigation. Journal of Mammalogy 98:378-385 DOI 10.1093/jmammal/gyx005 
560

561

562

563

564

565

566

567

568

569

570

571

572

573

574

575

576

577

578

579

580

581

582

583

584

585

586

587

588

589

590

591

592

593

594

595

596

597

598

599

600

601

602

603

Matzner S, Cullinan VI, and Duberstein CA. 2015. Two-dimensional thermal video analysis of offshore bird and bat flight. Ecological Informatics 30:20-28. DOI 10.1016/j.ecoinf.2015.09.001

McAlexander A. 2013. Evidence that bats perceive wind turbine surfaces to be water. Biology Masters of Science. Texas Christian University.

Mirzaei G, Majid MW, Ross J, Jamali MM, Gorsevski PV, Frizado J, and Bingman VP. 2012. Implementation of ant clustering algorithm for IR imagery in wind turbine applications. In: Garimella A, and Purdy CC, eds. 2012 Ieee 55th International Midwest Symposium on Circuits and Systems. New York: Ieee, 868-871.

Pfeiffer MB, Blackwell BF, and DeVault TL. 2018. Quantification of avian hazards to military aircraft and implications for wildlife management. PLOS ONE 13:e0206599. DOI 10.1371/journal.pone.0206599

Rodhouse TJ, Rodriguez, RM, Banner KM, Ormsbee PC, Barnett J, Irvine KM. 2019. Evidence of region-wide bat population decline from long-term monitoring and Bayesian occupancy model swith empirically informed priors. Ecology and Evolution 9:1107811088. DOI 10.1002/ece3.5612

Roemer C, Disca T, Coulon A, Bas Y. 2017. Bat flight height monitored from wind masts predicts mortality risk at wind farms. Biological Conservation 215:116-122. DOI 10.1016/j.biocon.2017.09.002

Rydell J, Bodganowicz W, Boonman A, Pettersson S, Suchecka E, Pomorski JJ. 2016. Bats may eat diurnal flies that rest on wind turbines. Mammalian Biology 81:331-339 DOI 10.1016/j.mambio.2016.01.005.

Smallwood KS. 2013. Comparing bird and bat fatality-rate estimates among North American wind-energy projects. Wildlife Society Bulletin 37:19-33. doi:10.1002/wsb.260

Swaddle JP, and Ingrassia NM. 2017. Using a sound field to reduce the risks of bird-strike: an experimental approach. Integrative and Comparative Biology 57:81-89. DOI 10.1093/icb/icx026

Thomsen OT. 2009. Sandwich materials for wind turbine blades - present and future. Journal of Sandwich Structures \& Materials 11:7-26. 10.1177/1099636208099710

Timm RM. 1989. Migration and molt patterns of red bats, Lasiurus borealis (Chiroptera: Vespertillionidae), in Illinois. Bulletin of the Chicago Academy of Sciences 14:1-7.

Valdez EW, Cryan PM. 2013. Insect prey eaten by hoary bats (Lasiurus cinereus) prior to fatal collisions with wind turbines. Western North American Naturalist 73:516-524 DOI 10.3398/064.073.0404.

Vasenev VI, Dovletyarova E, Cheng Z, and Valentini R. 2018. Megacities 2050: environmental consequences of urbanization. Proceedings of the VI International Conference on Landscape Architecture to Support City Sustainable Development. Cham, Switzerland: Springer.

Wang S, Wang S, and Smith P. 2015. Ecological impacts of wind farms on birds: questions, hypotheses, and research needs. Renewable and Sustainable Energy Reviews 44:599-607. DOI 10.1016/j.rser.2015.01.031

Warren JH, Sherwin RE, Ross C, Williams J, and Skalak SL. 2006. Applicability and reliability of external survey techniques when monitoring for Townsend's big-eared bat (Corynorhinus townsendii) in Pershing County, Nevada. Bat Research News 47:157-158. 
604 Watson JW, Keren IN, and Davies RW. 2018. Behavioral accommodation of nesting hawks to $605 \quad$ wind turbines. The Journal of Wildlife Management 82:1784-1793 DOI

$606 \quad 10.1002 /$ jwmg.21532

607 


\section{Figure 1}

Diagram of the thermal and night vision setups used at our site.

Thermal cameras were tested at 4 distances (A) $2 \mathrm{~m}$, (B) $25 \mathrm{~m}$, (C) $50 \mathrm{~m}$, and (D) $95 \mathrm{~m}$ from the wind turbine tower base, while night vision setups were kept at a distance of $2 \mathrm{~m}$ from the base and included 2 IR lights to illuminate the tower.

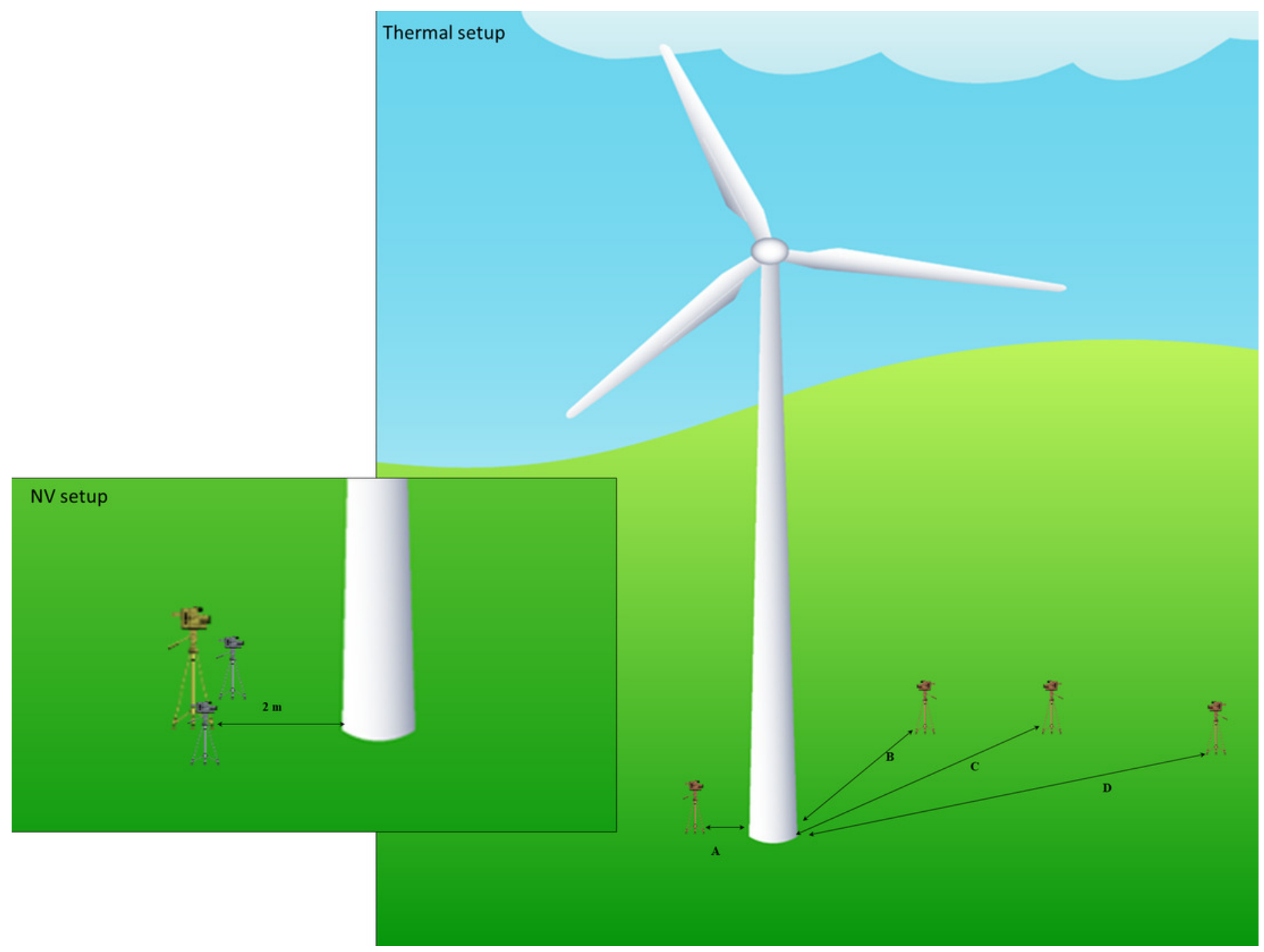


Figure 2

Representative images from thermal cameras (left) and night vision (right) fields-ofview showing the 3 categories of flying animals we observed at wind turbine towers.

(A-B) 'bats', (C-D) 'non-bats', and (E-F) 'undefined animals'. 
A

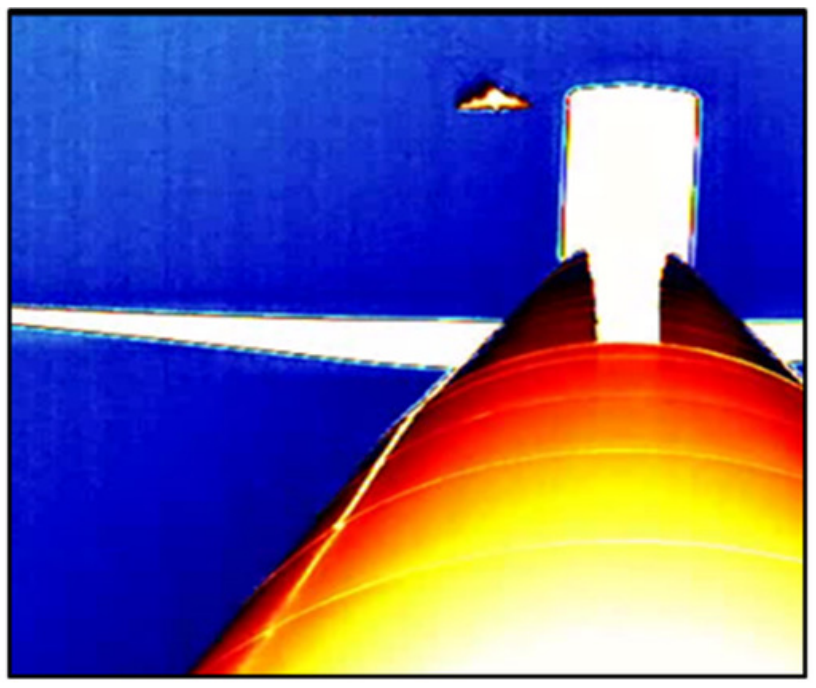

C

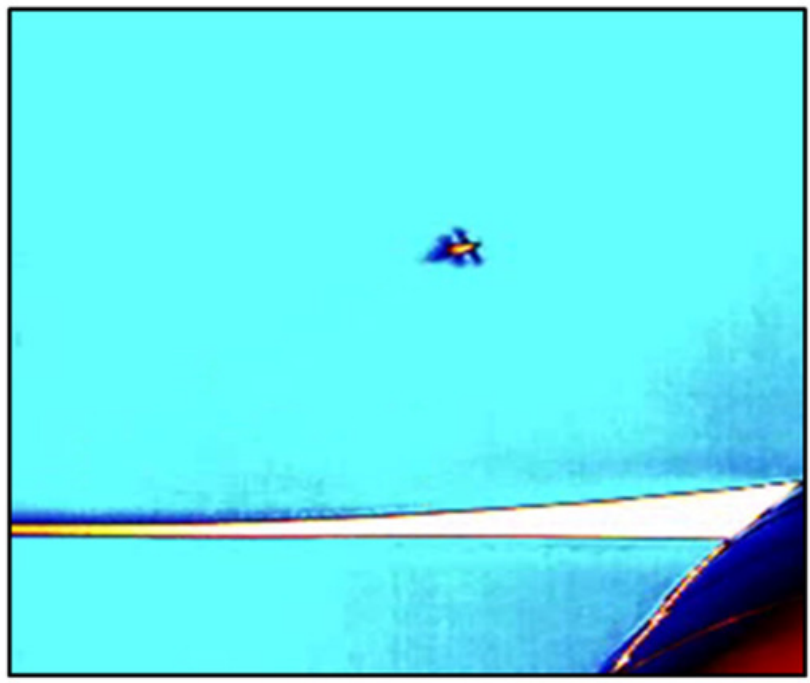

E

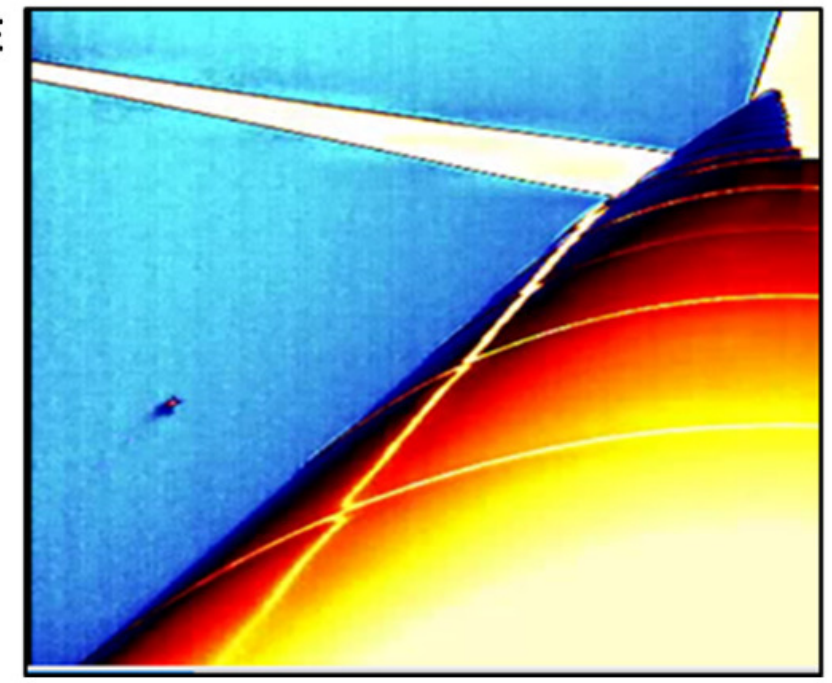

B

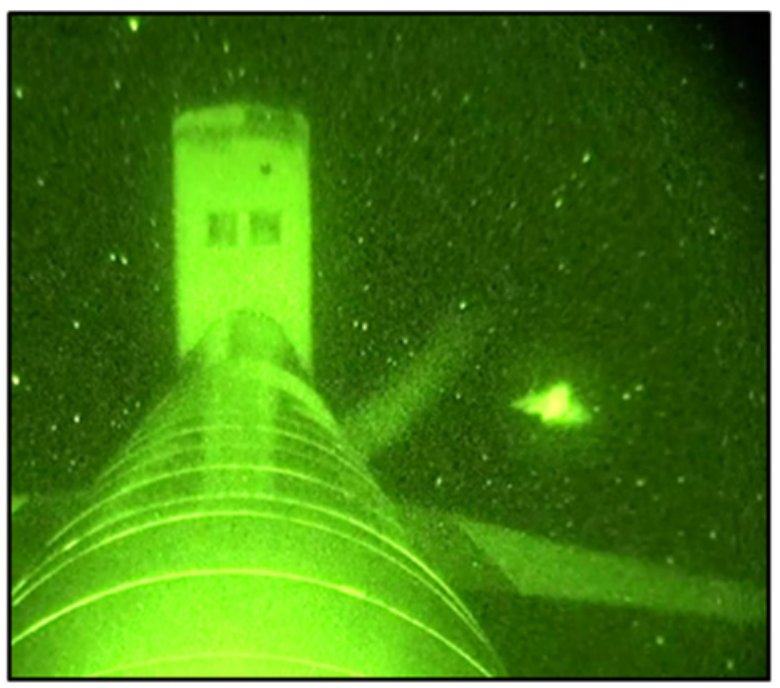

D

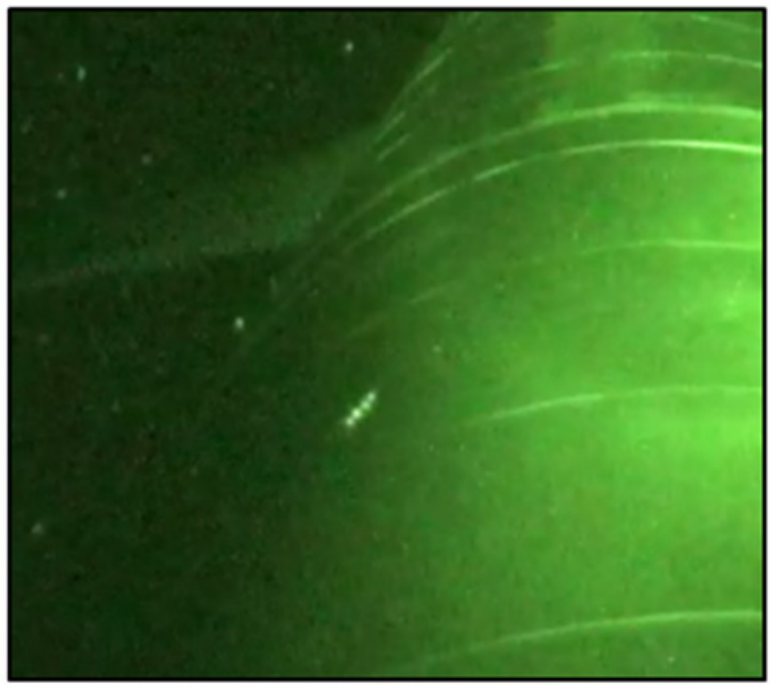

$\mathbf{F}$

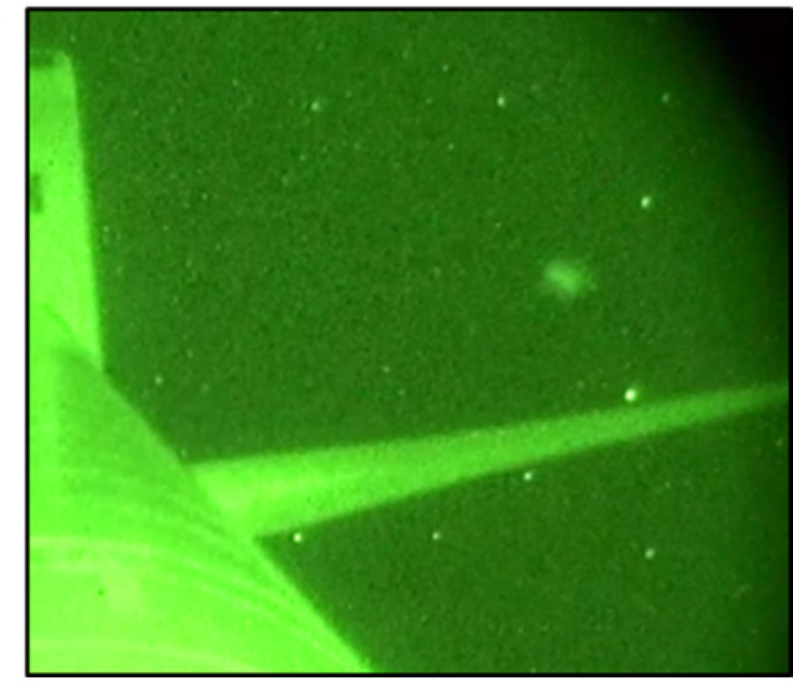




\section{Figure 3}

Mean \pm SE difference in the total number of (A) flying animals (includes bats, non-bats, and undefined animals) detected, (B) bats and non-bats identified, and (C) behaviors categorized.

Differences were calculated from the total number of detections recorded using thermal cameras at $2 \mathrm{~m}, 25 \mathrm{~m}, 50 \mathrm{~m}$, and $95 \mathrm{~m}$ from the wind turbine tower base minus the number of detections recorded by night vision technology at a distance of $2 \mathrm{~m}$ from the base. Numbers within the bars indicate the number of survey nights. 

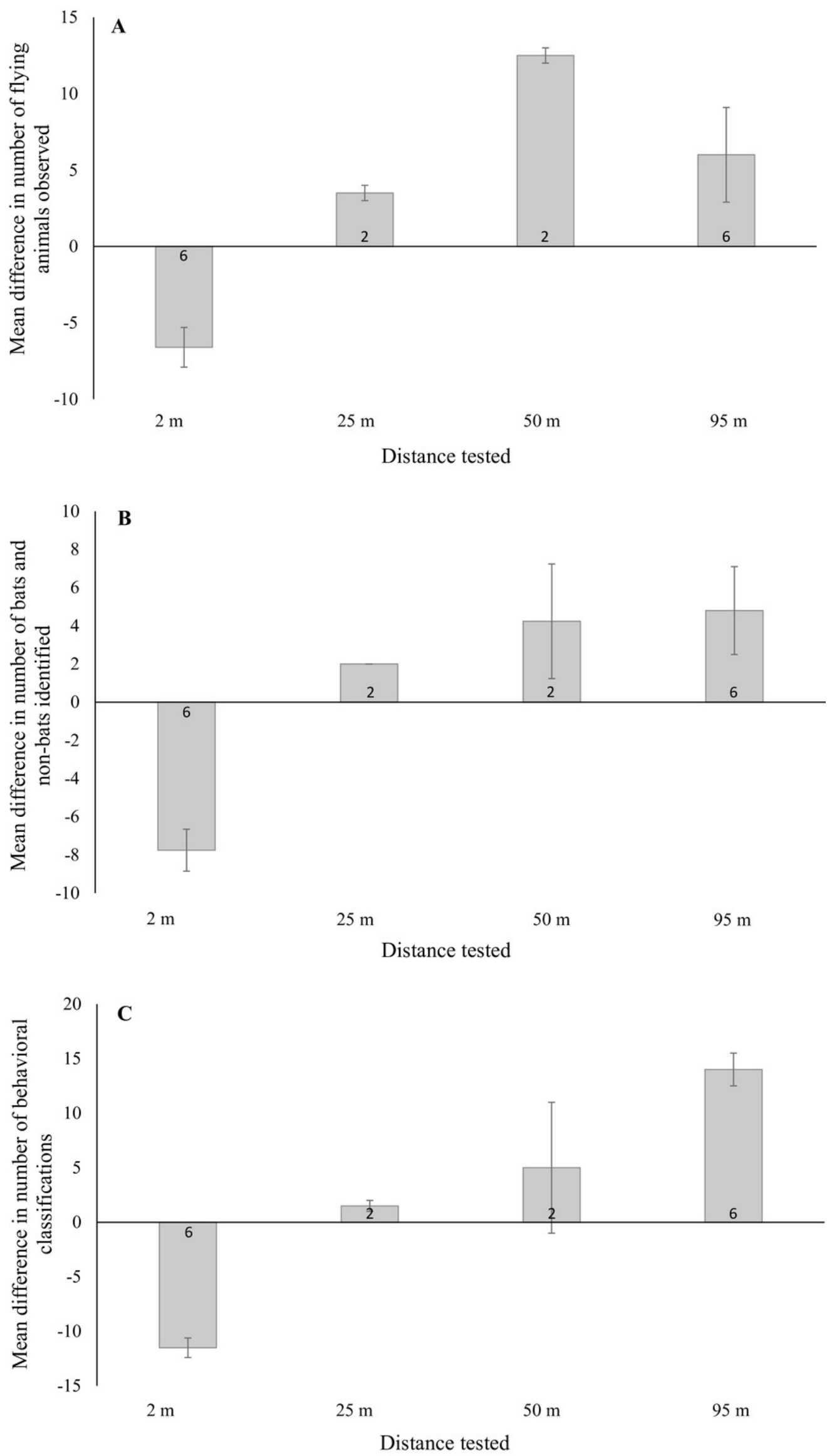
Figure 4

Mean \pm SE difference in (A) the total number of flying animals detected, (B) the number of batsand non-bats identified, and $(\mathbf{C})$ thenumber of behaviors categorized.

Differences were calculated from the total number of detections recorded using thermal cameras at $25 \mathrm{~m}$ and $50 \mathrm{~m}$ from the wind turbine tower base minus the number of detections recorded by the thermal camera at a distance of $2 \mathrm{~m}$ from the base.
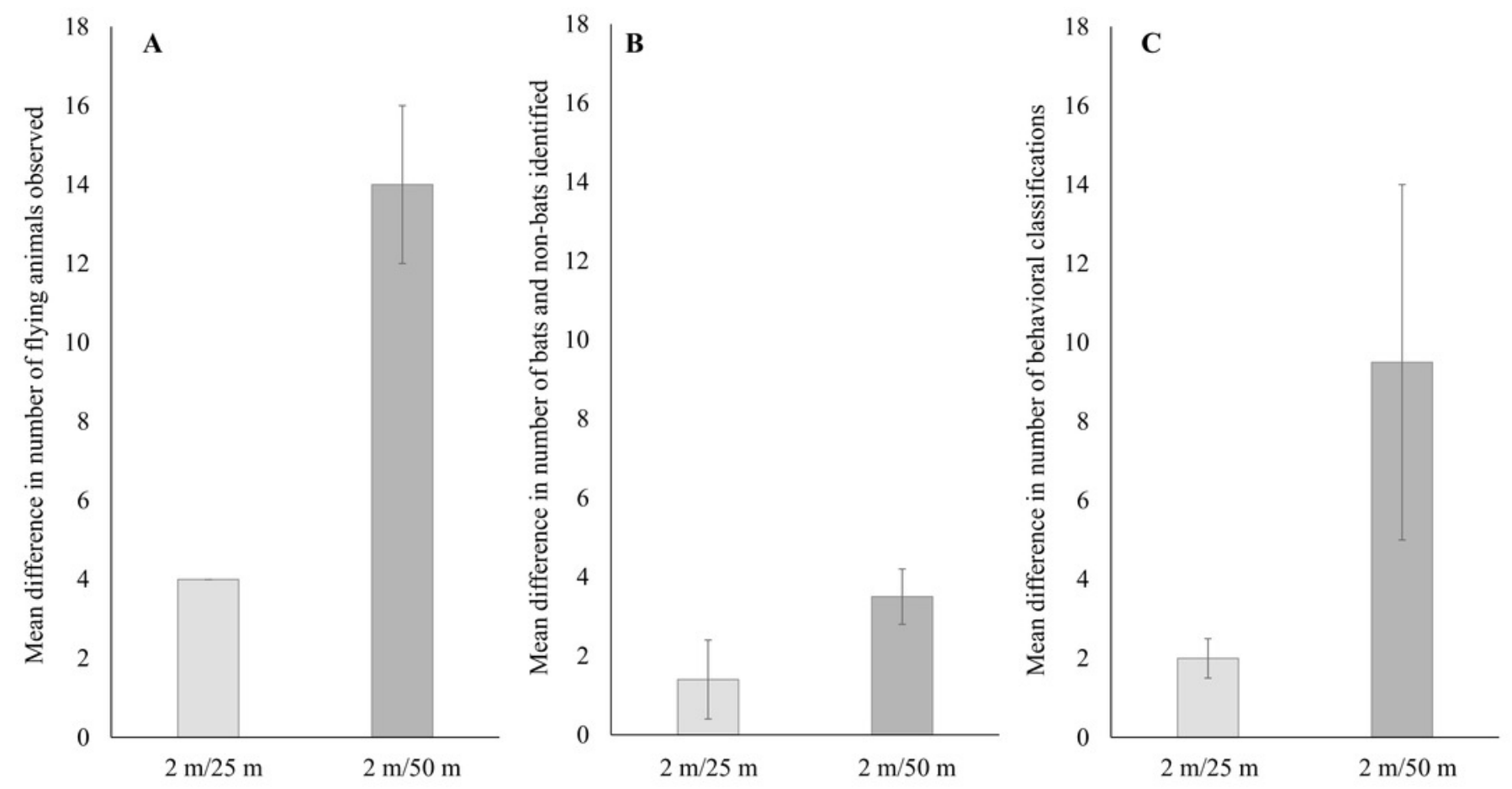

Distances tested 


\section{Figure 5}

Thermal and night vision images of bats (circled in red) approaching and passing closely in front of a wind turbine tower.

(A) shows that the bat is difficult to see when approaching the tower using night vision technology. (B-C) demonstrate that the bat is readily visible in front of the tower using night vision technology. In contrast, (D) shows that the bat is readily visible approaching the turbine tower using thermal cameras. (E-F) demonstrate that the bat becomes obscured by the infrared heat signature from the turbine tower.
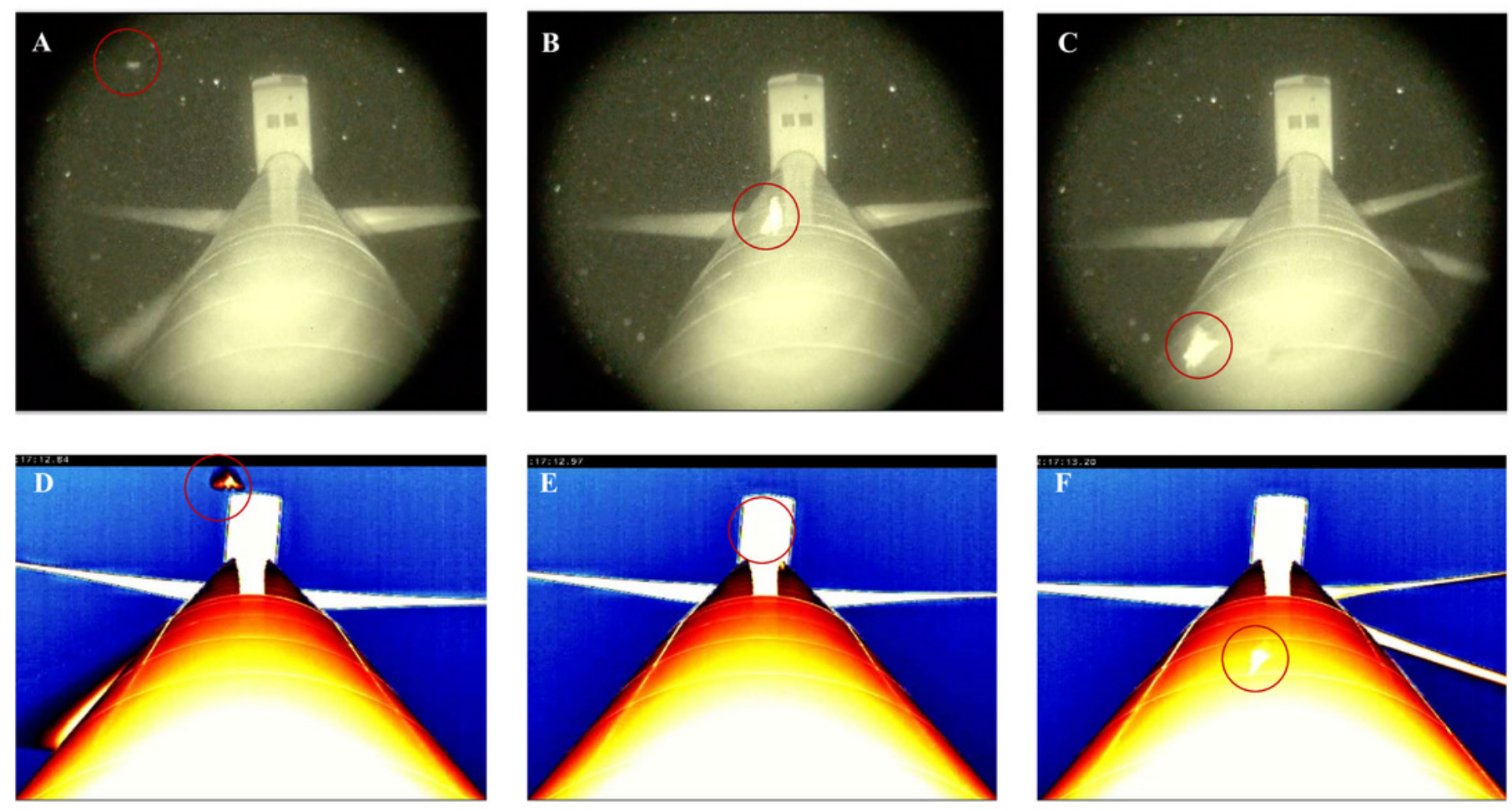


\section{Table $\mathbf{1}$ (on next page)}

$\mathrm{N}$ umbers of flying animals, bats, and non-bats, and associated behaviorsdetected in surveys using night vision and thermal camerasfrom 1 July to 10 August 2016 ( $n=28$ turbine nights).

Shown in parentheses are the numbers of flying animals, bats, and non-bats, and associated behaviors detected in thermal cameras at $2 \mathrm{~m}$ distances. Totals are given in bold. 


\begin{tabular}{|c|c|c|c|c|c|c|c|c|c|c|c|c|}
\hline \multirow[b]{2}{*}{$\begin{array}{c}\text { Survey } \\
\text { nights }\end{array}$} & \multicolumn{4}{|c|}{ Thermal cameras } & \multicolumn{8}{|c|}{ Night vision } \\
\hline & $\begin{array}{c}\text { \# of } \\
\text { turbines } \\
\text { surveyed }\end{array}$ & $\begin{array}{c}\text { Distance } \\
\text { from } \\
\text { turbine } \\
\text { base }\end{array}$ & $\begin{array}{l}\text { \# flying } \\
\text { animals }\end{array}$ & \# bats & $\begin{array}{c}\# \text { non- } \\
\text { bats }\end{array}$ & $\begin{array}{c}\# \\
\text { behaviors } \\
\text { identified }\end{array}$ & $\begin{array}{c}\# \text { of } \\
\text { contact } \\
\text { behaviors }\end{array}$ & $\begin{array}{l}\text { \# flying } \\
\text { animals }\end{array}$ & $\begin{array}{c}\# \\
\text { bats }\end{array}$ & $\begin{array}{c}\text { \# non- } \\
\text { bats }\end{array}$ & $\begin{array}{c}\# \\
\text { behaviors } \\
\text { identified }\end{array}$ & $\begin{array}{c}\text { \# of } \\
\text { contact } \\
\text { behaviors }\end{array}$ \\
\hline 6 & 2 & $2 \mathrm{~m}$ & 237 & 68 & 119 & 66 & 2 & 159 & 22 & 72 & 20 & 0 \\
\hline 2 & 1 & $25(2) \mathrm{m}$ & $5(13)$ & $3(7)$ & $1(4)$ & $3(7)$ & $0(0)$ & 12 & 5 & 3 & 5 & 0 \\
\hline 2 & 1 & $50(2) \mathrm{m}$ & $14(42)$ & $5(25)$ & $0(8)$ & $5(25)$ & $0(0)$ & 39 & 15 & 8 & 15 & 0 \\
\hline 6 & 2 & $95 \mathrm{~m}$ & 3 & 2 & 0 & 2 & 0 & 27 & 19 & 2 & 19 & 1 \\
\hline 16 & & & $\begin{array}{c}259(55) \\
\mathbf{3 1 4}\end{array}$ & $\begin{array}{c}78(32) \\
110\end{array}$ & $\begin{array}{c}120(12) \\
132\end{array}$ & $\begin{array}{c}76(32) \\
108\end{array}$ & $\begin{array}{c}2(0) \\
2\end{array}$ & 237 & 61 & 85 & 59 & 1 \\
\hline
\end{tabular}

2 